\title{
CFD Analysis of a Decay Tank and a Siphon Breaker for an Innovative Integrated Passive Safety System for a Research Reactor
}

\author{
Kwon-Yeong Lee, ${ }^{1}$ Hyun-Gi Yoon, ${ }^{2}$ and Dong Kyou Park ${ }^{3}$ \\ ${ }^{1}$ Handong Global University, 558 Handong-ro, Buk-gu, Pohang, Gyeongbuk 37554, Republic of Korea \\ ${ }^{2}$ Korea Atomic Energy Research Institute, 111 Daedeok-daero, Yuseong-gu, Daejeon 34057, Republic of Korea \\ ${ }^{3}$ Korea University of Technology and Education, 1600 Chungjeol-ro, Byeongcheon-myeon, Dongnam-gu, Cheonan City, \\ Chungnam 31253, Republic of Korea \\ Correspondence should be addressed to Dong Kyou Park; pdongkyou@koreatech.ac.kr
}

Received 25 March 2017; Accepted 4 July 2017; Published 10 August 2017

Academic Editor: Domenico Paladino

Copyright $\odot 2017$ Kwon-Yeong Lee et al. This is an open access article distributed under the Creative Commons Attribution License, which permits unrestricted use, distribution, and reproduction in any medium, provided the original work is properly cited.

\begin{abstract}
An innovative integrated passive safety system for a research reactor is proposed in this study to improve the safety of the research reactor. This integrated system has three functions in the facility as a decay tank, siphon breaker, and long-term cooling tank. This paper also deals with the process of designing and optimizing the decay tank and the siphon breaker of the integrated passive safety system. At first, the decay tank was designed and improved step by step, while considering the computational fluid dynamics analysis results. Consequently, we could satisfy the design requirements of the decay tank. In addition, the performance of a new type of siphon breaker that was installed in the final decay tank model was tested. We designed an 18-inch diameter siphon breaker at the top of the decay tank's third section, and we could observe the breaking of the siphon that prevented the occurrence of a severe accident in the research reactor. By locating the siphon breaker at the third section of the decay tank, we could also use the coolant of the front three sections for long-term cooling of the research reactor.
\end{abstract}

\section{Introduction}

A research reactor is a nuclear facility used to produce neutron transmutation doping and radioisotopes and to conduct research using neutrons in the reactor, for example, neutron radiography. The Korea Atomic Energy Research Institute (KAERI) is now designing the KIJANG Research Reactor (KJRR), which is a $15 \mathrm{MW}$ reactor. Before KJRR, KAERI had designed and exported a $5 \mathrm{MW}$ research reactor named Jordan Research and Training Reactor (JRTR) to Jordan. The safety related devices in the JRTR were the decay tank and siphon breaker as shown in Figures 1 and 2, respectively. The decay tank is a device that provides sufficient flow residence time to decrease the $\mathrm{N}-16$ activity in the primary coolant passing through the reactor core. N-16 has the most highenergy $\gamma$-rays among the several types of radionuclides in the primary coolant. The N-16 dose rate at the inlet of the decay tank is much greater than those of other radionuclides. Fortunately, its half-life is very short, only $7.13 \mathrm{~s}$, and the dose rate of N-16 decreases as the flow residence time increases dramatically. Therefore, it could be advantageous to design other equipment, such as pumps, heat exchangers, valves, and so forth, in the primary cooling system (PCS) of the research reactor if the coolant is delayed in the decay tank to reduce the radiation level of N-16 sufficiently during the normal operation of the research reactor. In addition, the siphon breaker is a safety device used to prevent a severe accident such as a loss of coolant accident (LOCA) in research reactors. In the event of an accident such as a pipe rupture, all the cooling water inside the decay tank will leak out due to the siphon phenomenon caused by the pressure difference. The water level of the reactor pool would then be lowered and the core located at the bottom of the reactor pool would be exposed to air. As the possibility of secondary damage due to 


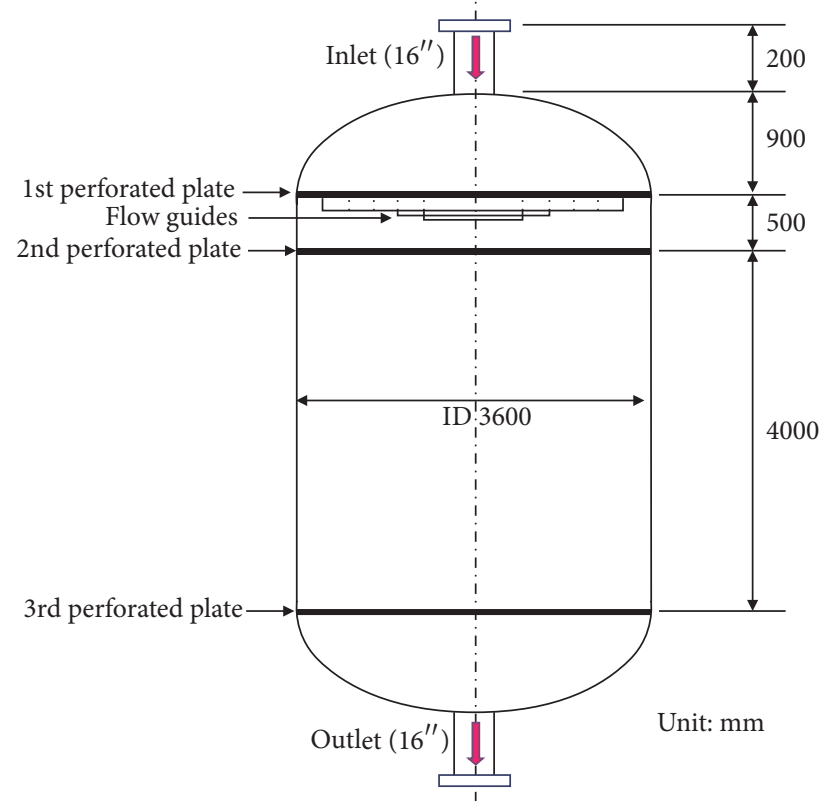

Figure 1: Previous decay tank model [1, 2].

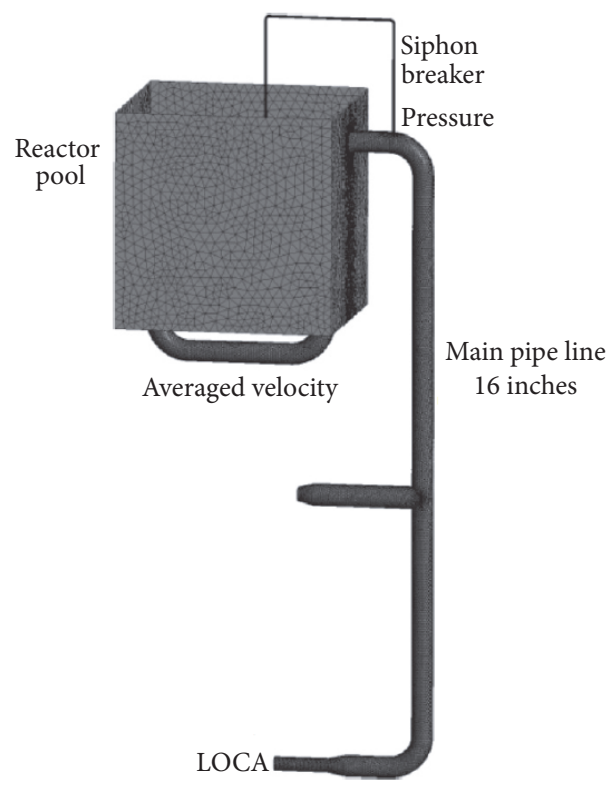

FIgURE 2: Previous siphon breaker model [8].

overheating of the core thus increases, the siphon breaker is operated immediately after the accident occurs and an inrush of air through the siphon breaker prevents a water efflux due to the siphon phenomenon. Therefore, the level of the reactor pool is maintained at an appropriate level to prevent the overheating of the core.

Jeong et al. [1] estimated the flow residence time using a computational fluid dynamics (CFD) code, ANSYS-CFX, in a decay tank that consisted of a cylinder and two elliptical hemispheres with three perforated plates. Even though they recommended the adoption of an unsteady simulation of a user-defined scalar method to estimate the minimum flow residence time, the results thus obtained were almost the same as those obtained using the particle tracking method. In addition, Jeong et al. [2] studied the decay tank using another CFD code, FLUENT, to confirm the relationship between the fluid distribution with the residence time and the total dose rate. The flow residence time was estimated using a particle tracking method such as the discrete phase model (DPM) in FLUENT [3].

To investigate the siphon breaker, McDonald and Marten [4] carried out an experiment in order to confirm the performance of siphon breaking valve as an actively operation type. Neill and Stephens [5] performed an experiment using a siphon breaker as a passively operated device in a smallsized pipe. Sakurai [6] proposed an analytical model to analyze the siphon breaking where a fully separate airwater flow model was applied. Kang [7] performed real-scale verification experiments using a large-sized pipe. The results thus obtained could be applied to the actual siphon breaker design in the JRTR. Seo et al. [8] proposed an analytical model for the experimental results of the siphon breaker obtained using CFD. Experimental data are compared with numerical results using the inhomogeneous two-phase model with an SST turbulent model. However, previous studies have not presented a satisfactory theoretical model because the calculation of siphon breaking is overly complex. Lee and Kim [9] developed a theoretical model that can predict the progress and the result of the siphon breaking phenomenon well. The established theoretical model is based on Bernoulli's equation and includes the Chisholm model for analyzing two-phase flow. Moreover, Lee and Kim [10] developed the siphon breaker simulation program to use the model established using Microsoft Foundation Class programming.

Comparing with a $5 \mathrm{MW}$ research reactor, the sizes or numbers of the decay tank and siphon breaker should be increased for a $15 \mathrm{MW}$ research reactor. However, the design and manufacture of such huge devices are quite difficult. In addition, long-term cooling after the reactor shuts down in an accident should be considered because the decay heat for a $15 \mathrm{MW}$ research reactor is much greater than that of a $5 \mathrm{MW}$ research reactor. Therefore, Lee et al. [11] suggested a new design for the long-term cooling of a research reactor that comprised a dam and small pipes between the reactor pool and the service pool.

By combining the functions of all the devices mentioned above, the new concept of an integrated passive safety facility for a research reactor was developed in this study. This system can perform the three functions of a decay tank, which reduces the radioactivity by delaying the passing time of the coolant in the normal operation of the research reactor; siphon breaker, which prevents coolant loss when a LOCA occurs; and long-term cooling tank, which can remove the decay heat of the core by supplying the coolant to the reactor pool passively. This paper is especially focused on a simulation analysis for the design and optimization of the integrated passive safety facility in a $15 \mathrm{MW}$ research reactor. This study is divided into two parts consisting of a decay tank analysis and a siphon breaker analysis, respectively. The aim of this research is to design and optimize the structure of the 
TABLE 1: Operating conditions of integrated passive safety system.

\begin{tabular}{lccc}
\hline Operation conditions & Normal operation & \multicolumn{2}{c}{ LOCA accident } \\
\hline Involved parts & Section A + Section B + Section C & Section B + siphon breaking valve & Section A + Section B \\
Functions & Decay tank & Siphon breaker & Long-term cooling tank \\
\hline
\end{tabular}

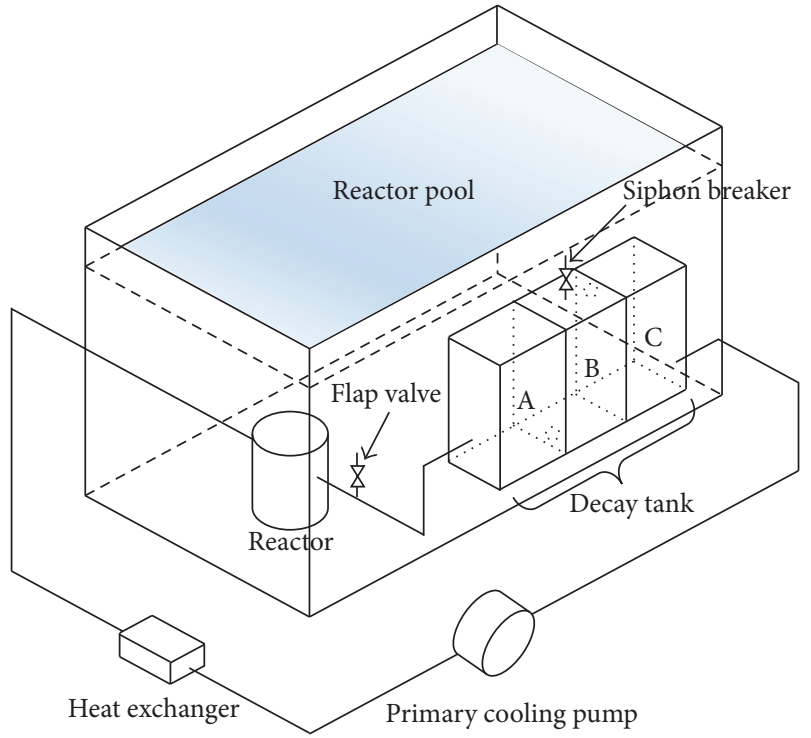

FIGURE 3: Schematic of integrated passive safety system.

two devices, the decay tank, and siphon breaker, based on the results of the CFD analysis.

At first, the decay tank was examined to optimize and design the proposed facility. The ease of maintenance of the decay tank is essential as the internal part of the decay tank will be radioactive. For this reason, the internal part of the decay tank model in this research is much simpler than that of the existing decay tank designs. In this case, in order to determine if the decay tank is properly designed, we used the particle tracking method to determine whether the fastest particles would take more than 60 s to pass through the decay tank. In addition, we attempted to confirm that the siphon phenomenon was properly cut off when the siphon breaker was operated in a new safety facility.

\section{System Description}

A new safety system for a research reactor, which integrates the decay tank, siphon breaker, and long-term cooling tank as a single facility, is suggested as shown in Figure 3 to improve the space efficiency and the ease of manufacturing and maintenance. The number and size of the sections of the facility can be decided by the quantity of evaporated water during long-term cooling and the flow residence time. Table 1 shows the operating conditions of this integrated passive safety system according to the status of the research reactor. The details of each function are as shown below.

2.1. Decay Tank. In the normal operation of the research reactor, the coolant passing the reactor core contains $\mathrm{N}-16$, which is highly radioactive but has a short half-life. Therefore, the decay tank in a PCS should be able to contain the coolant for sufficient time to satisfy the design requirement of delaying the flow. One of the existing design methods is the use of perforated plates inside a hemispherical cylinder, which was used by Jeong et al. $[1,2]$. Another existing design method suggested by Seo et al. [12] can increase the flow residence time through the internal vertical baffle, the outer vertical baffle, and the dispersion pipe connected to the internal vertical baffle. However, the maintenance of existing decay tank models is difficult because of their complicated internal parts. Therefore, the internal parts of the decay tank should be simplified for the convenience of maintenance and manufacture. The internal part of the suggested decay tank model in this research is much simpler than that of existing decay tank designs. Sections A, B, and C perform the function of the decay tank in normal operation. As shown in Figure 4(a), the coolant that flows into Section A stays inside Section A for a sufficient flow residence time. After that, the coolant flows into Section B through the connection region at the bottom of Section $B$. Then, the coolant flows into Section $\mathrm{C}$ through the connection region at the top of Section $\mathrm{C}$ and exits through the main pipe of the PCS at the bottom of Section C. Therefore, this simple model ensures a sufficient flow residence time and is convenient for performing maintenance work.

2.2. Siphon Breaker. In the research reactor, the reactor core is cooled by natural circulation through the flap valves to the reactor pool after the primary cooling pump (PCP) is turned off. The pool water itself is the ultimate heat sink for the core decay heat. Thus, it is very important to guarantee that the pool water level is higher than the minimum level from a safety point of view. The JRTR and KJRR are openpool-type research reactors and have downward core flows. To meet the required net positive suction head (NPSHr) of the PCPs, some components of the PCS are installed below the core level. When a postulated pipe break occurs below the reactor core position, the pool water can be drained below the core owing to the siphon phenomenon, and the core will then not be cooled by natural circulation. Therefore, siphon breakers with siphon breaking valves and siphon breaking line are installed in the PCS to limit the pool water drainage during and after all postulated initiating events. Because the open-pool-type reactor operates at low-pressure and lowtemperature conditions, a guillotine break LOCA is almost impossible. However, a pump casing rupture due to the failure of a moving part could be considered conservatively.

In this study, a new type of siphon breaker was suggested. It consists of siphon breaking shut-off valves and a differential pressure transmitter in Section B of Figure 3. At the top of Section $\mathrm{B}$, the air pours in by opening the siphon breaking 


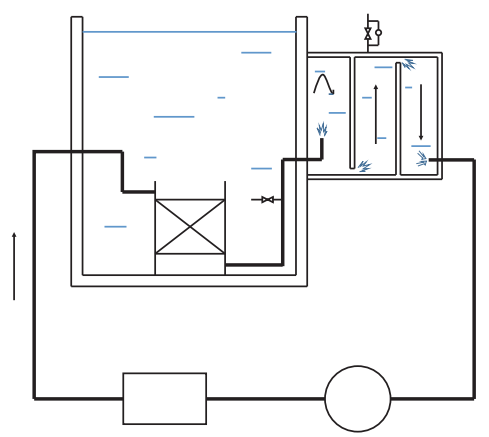

(a) Decay tank

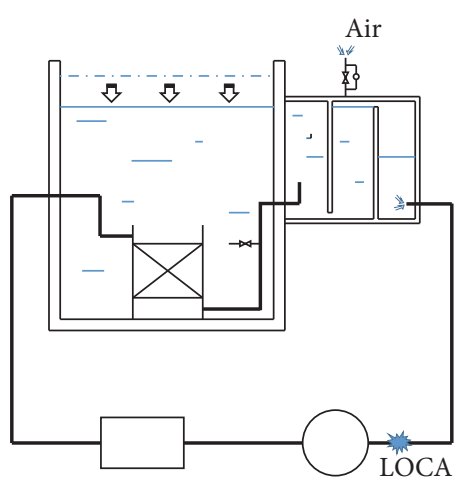

(b) Siphon breaker

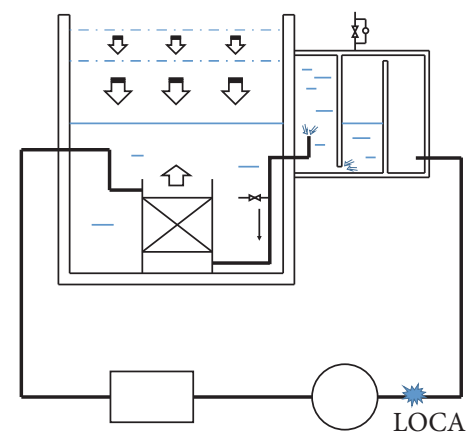

(c) Long-term cooling tank

FIGURE 4: Operation modes of integrated passive safety system.

shut-off valves when siphoning occurs. The air fills Section B up to the connection region at the top and stops the siphon phenomenon by shutting the coolant flow off as shown in Figure 4(b). In JRTR, AOVs (air-operated valves) are installed as the siphon breaking valves. The AOVs are designed as fail-open to satisfy the safety function when there are malfunctions in the compressed air system or electrical power system. Same practices maybe applied in this new system.

The larger the diameter of the primary cooling pipe, the greater the amount of air that is required to break the siphon, and the size of the siphon breaking valve increases proportionally. Moreover, this causes some difficulties in the design, production, and testing of the siphon breaking valve. Therefore, it would be easier to install multiple small siphon breaking valves using the space above Section B. In addition, this method also helps to lower the risk of valve malfunction. When multiple valves are installed, all the valves except the malfunctioning valve can be opened to stop the siphon breaking phenomenon. To detect the malfunctioning of the valves, a differential pressure transmitter is installed to measure the differential pressure between the areas upstream and downstream of the valves. The area upstream of the valves is exposed to the atmosphere and has atmospheric pressure while that downstream of the valves is connected to Section $B$ and has a negative pressure. And the differential pressure transmitter always measures as a constant value. However, if the valve is opened in normal operation, the gauge will detect the difference and, hence, check whether there is valve malfunction.

2.3. Long-Term Cooling Tank. The rapid loss of coolant from the reactor is stopped by the siphon breaker, as shown in Figure 4(b). At the moment the water level of Section B and the research pool are the same. However, the siphon breaking phenomenon lasts for only a few minutes while the core long-term cooling takes several days. Therefore, as soon as the siphon breaking phenomenon is stopped, the water evaporates for days owing to the remaining core decay heat. Therefore, sufficient coolant is required to be refilled. Sections A and B then act as the long-term cooling tank and compensate for the evaporated water in the reactor pool as shown in Figure 4(c). For $15 \mathrm{MWt}$ KIRR, the evaporation rate is about $0.0664 \mathrm{~kg} / \mathrm{s}$ if the residual heat is assumed as $1 \%$ of full power. If we also assume the available volume of the longterm cooling tank is $60 \mathrm{~m}^{3}$, then it will be sufficient volume to remove decay heat during additional 10 days.

\section{CFD Analysis}

3.1. Decay Tank. Two types of meshes are used for the numerical simulation. One mesh is tetrahedron-shaped and the other is hexahedron-shaped. The number of meshes of the final model was 300,000 based on the grid dependency test. The simulation results of the flow residence time are almost the same with larger mesh numbers.

Two types of turbulence stress models, the realizable $k-\varepsilon$ model, and transition shear stress transport (SST) model, are used to simulate the flow field and flow residence time. The realizable $k-\varepsilon$ model has several characteristics that make it suitable for complex shear flows involving rapid strain, moderate swirl, vortices, and locally transitional flows (e.g., boundary layer separation, massive separation, and room ventilation).

The SST model is a hybrid two-equation model that combines the advantages of both the $k-\varepsilon$ realizable model and $k-\omega$ model. At wall adjacent sections, the $k-\omega$ model is used and boundary layer is resolved if sufficient mesh resolution is available. Wilcox's original $k-\omega$ model is overly sensitive to the freestream value (boundary condition) of $\omega$ and blended to the $k-\varepsilon$ model outside the boundary layer. The SST model is a good compromise between the $k-\varepsilon$ and $k-\omega$ models.

Jeong et al. [2] used the SST model to analyze turbulent flow because complex flow fields are generated across perforated plates. There is no significant difference between the $k-\varepsilon$ realizable model and the SST model in our research because the flow fields are simple. The flow fields of the decay tank are almost the same as an internal duct flow. The $k-\varepsilon$ realizable model is selected to calculate the flow residence time because the simulation results of this new system do not show strong swirl flow, and the internal flow fields are almost straight flows at each section of the decay tank. In this test, the automatic wall treatment model was used as a wall function. Four different shapes of the decay tank are considered in this research, as shown in Figures 5 and 6, to improve its performance. 


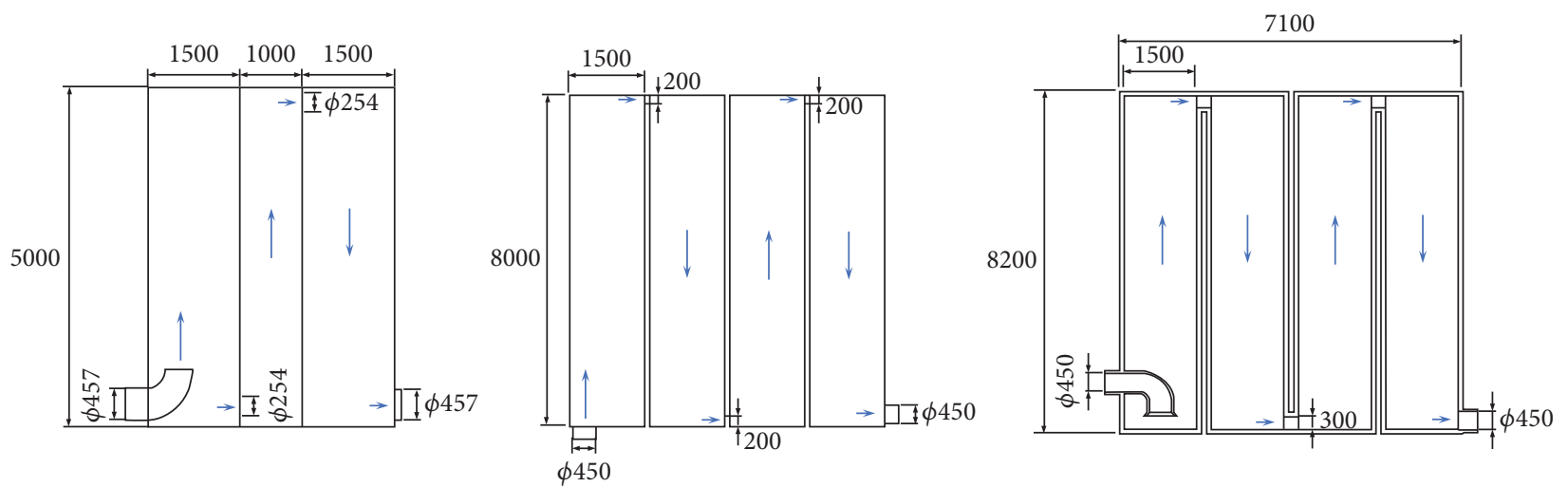

FIgURE 5: Schematics of first, second, and third decay tank models.
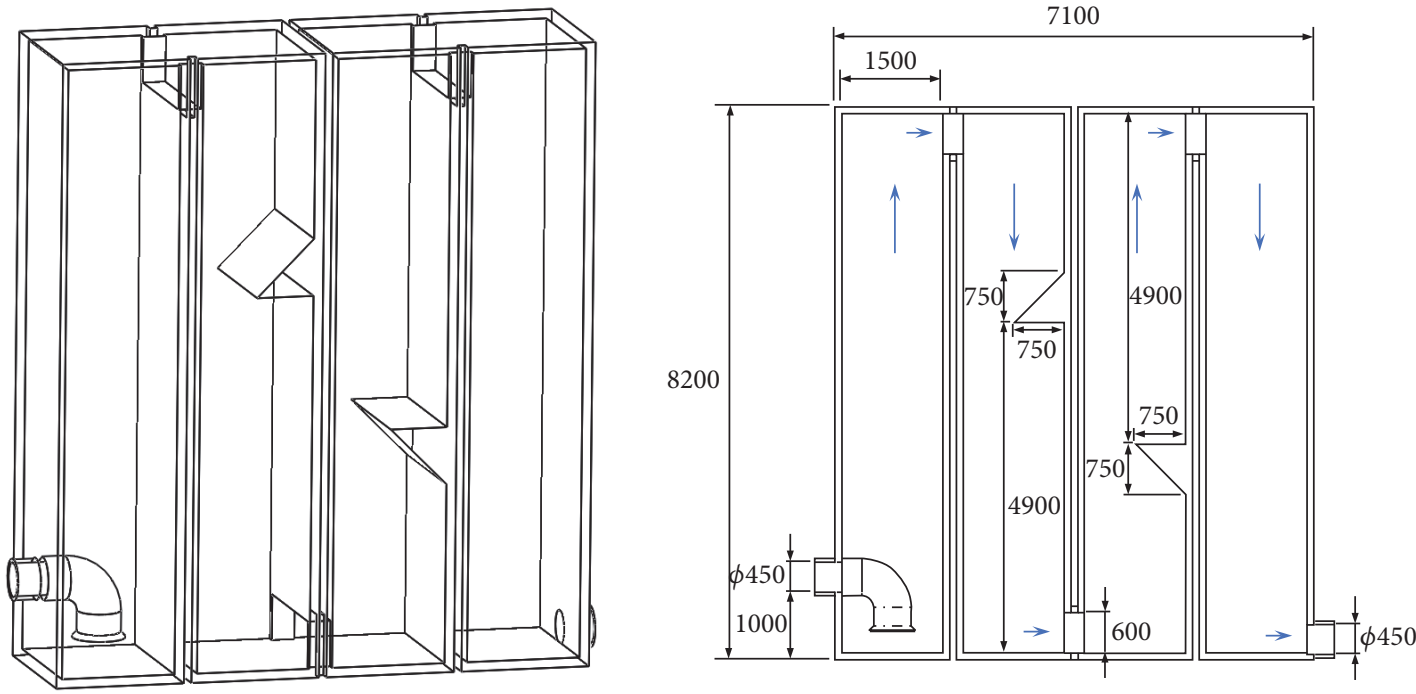

FIGURE 6: Projected view and schematic of final (fourth) decay tank model.

The mesh model of the final decay tank model of Figure 6 is shown in Figure 7. We did not use the automesh method, which creates a tetrahedron-shaped mesh, for all the sections. The tetrahedron-shaped mesh is used at the parts in which swirling and flow complexity were expected, the hexahedronshaped mesh was used for the rest of the body, and the sweepable method was used for the pipe. The mesh size was determined based on the grid dependency test. Among the mesh sizes having almost same residence times, the maximum number of mesh is used in this calculation to obtain the smooth flow field.

A minimum of $60 \mathrm{~s}$ of flow residence time is given as the design requirement for the decay tank. This residence time is selected based on the required dose rate at the decay tank outlet. Jeong et al. [2] showed that the dose rate for N-16 becomes smaller than that for the other radionuclides when the flow residence time is greater than $60 \mathrm{~s}$. This is a conservative requirement as compared to the suggested residence time for the radiation design by them. The suggested minimum flow residence time is only $16 \mathrm{~s}$.
The DPM function is used for the particle tracking method to calculate whether the minimum flow residence time is longer than $60 \mathrm{~s}$ in the decay tank. One thousand floating particles were used in this calculation, which have the same density as that of the water. The feasibility of using the DPM function and the SST model of the function was already verified by Jeong et al. [2].

3.2. Siphon Breaker. The geometrical and mesh models are presented in Figure 8. The decay tank model of Figure 7 is used to simulate the siphon breaking phenomenon. The reactor pool, siphon breaker, and connected pipelines are included in the numerical simulation. The mesh size of the reactor pool is relatively coarse because the flow rate of the reactor pool region is low, and there are no complex flow fields. In addition, a fine mesh is used at the regions that include the siphon breaker and the connection between the third and fourth sections because a two-phase flow of the water and air is generated at that region. 


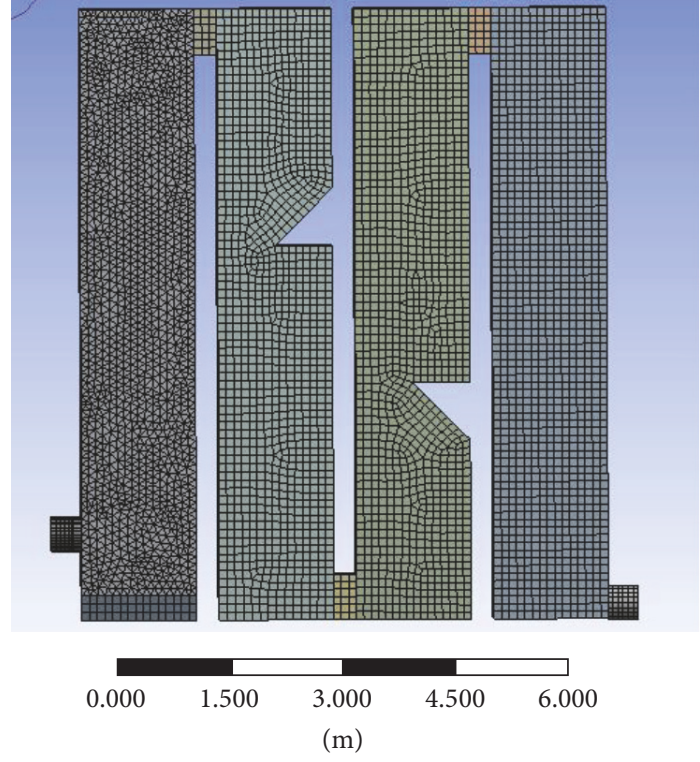

FIGURE 7: Mesh modeling of final decay tank model.

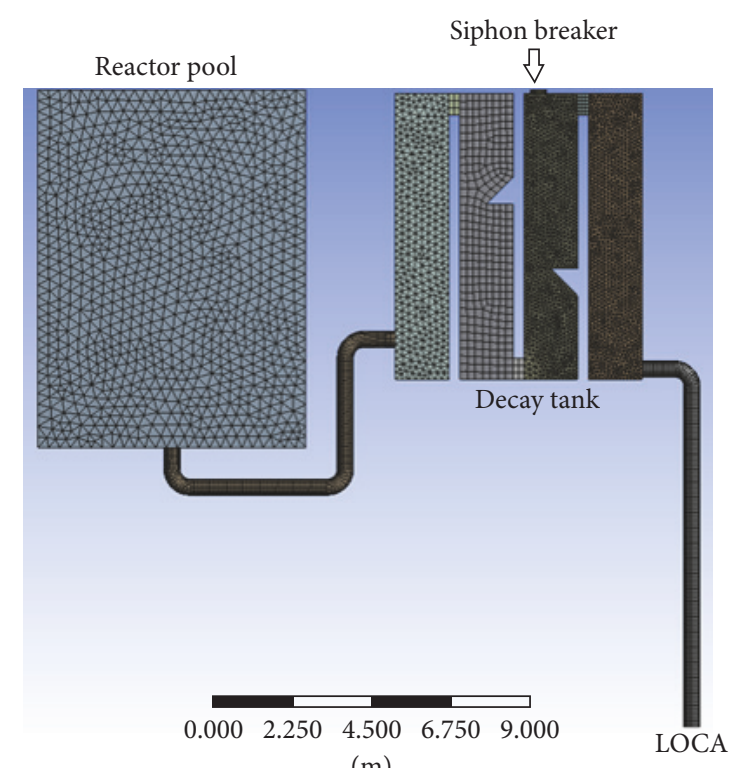

FIGURE 8: Mesh modeling for siphon breaker evaluation.

The design of the siphon breaker was based on the final decay tank model. The siphon breaking valve is located at the third section of the final decay tank model as shown in Figure 8, in order to use the cooling water of the first, second, and third sections after the siphon breaking phenomenon is complete. An 18-inch siphon breaking valve is used in this calculation. The siphon breaking phenomenon is very complex and high computational power is required to obtain an accurate solution. An 18-inch siphon breaking valve and the mesh of Figure 8 are selected in consideration of the Courant number. A smaller-sized mesh and siphon breaking valve should be used to obtain a comprehensive design. However, the aim of this research is to develop the integrated decay tank system and to simulate the siphon breaking phenomenon.

The volume of fluid model is used to simulate the physical phenomena of the water-air phase. The realizable $k-\varepsilon$ model is used in this calculation. The transient calculation method is used to observe the change in the two-phase flow field with time. An accurate calculation result is obtained when the time step considered is small. In the transient method, the Courant number controls the time step. A time step of $0.01-0.05 \mathrm{~s}$ is used in this calculation. A Courant number $(=$ velocity $\times$ time step/mesh size) of 1 is used in this simulation in consideration of the velocity field at the region of the siphon breaker. The purpose of this simulation is to verify the siphon breaking phenomenon in the newly suggested safety system. More CFD studies will be required to decide the size of the siphon breaker.

\section{Results and Discussion}

4.1. Analysis Results of Decay Tank. The geometrical data and flow residence time are described in Table 2. The first model of the decay tank is designed based on the first idea explained in the system description and Figure 4(a). An improved and optimized design concept are adopted in the decay tank design to make the flow field stable and obtain $60 \mathrm{~s}$ of flow residence time. The flow residence time of the first model is approximately $14 \mathrm{~s}$. The flow fields are complex at each section of the decay tank as shown in Figure 10. The inlet flow from the pipeline goes directly to the inside of the decay tank. The flow velocity is approximately $2 \mathrm{~m} / \mathrm{s}$ owing to the short flow distance and narrow volume. Even though this result is similar to the flow residence time suggested by Jeong et al. [2], we decided to improve the decay tank design using a conservative approach towards the radiation protection aspect.

First, we scaled up the size of the decay tank section because the magnitudes of the flow distance and volume of the section were too small in the first model. The height is increased from $5 \mathrm{~m}$ to $8 \mathrm{~m}$, and one more section was added. After increasing the tank size, the obtained residence time was $43 \mathrm{~s}$ in the second model, but it still did not satisfy the design requirement of $60 \mathrm{~s}$. Moreover, the flow filed of the connecting parts between each section were yet to be modified because the flow velocity was approximately $1.4-1.6 \mathrm{~m} / \mathrm{s}$ in this region as shown in the second model in Figure 10. To solve this problem, it seems necessary to modify the size of the connecting region. Furthermore, when the inlet flow is injected vertically, the flow field of the first section is directly affected by the inlet pipe velocity, and it is very difficult to control the flow velocity inside the decay tank. In the third model of Figure 10, the connection region is expanded and the injected direction of the inlet flow is changed to the downward direction in order to control the flow rate. By expanding the area of the connection region (from $1.5 \mathrm{~m} \times 0.3 \mathrm{~m}$ to $1.8 \mathrm{~m} \times 0.6 \mathrm{~m}$ ), the flow velocity is controlled and slowed down after the flow passes through the connection regions.

In the previous models' results, a phenomenon occurs in which the flow uses only one side of the section after it 


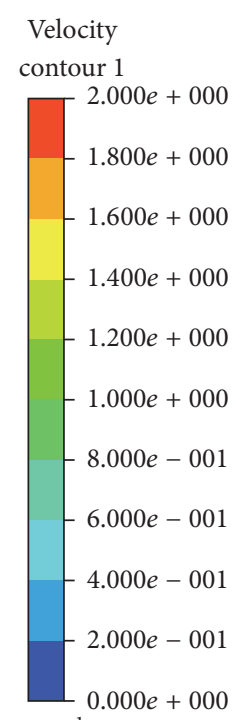

$\left(\mathrm{m} \mathrm{s}^{-1}\right)$

Velocity

contour 1

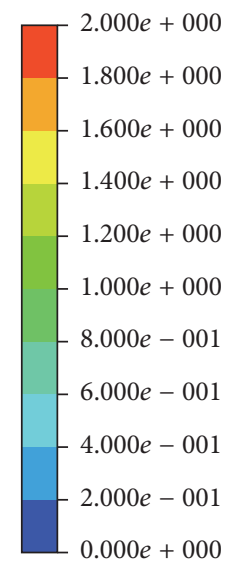

$\left(\mathrm{m} \mathrm{s}^{-1}\right)$

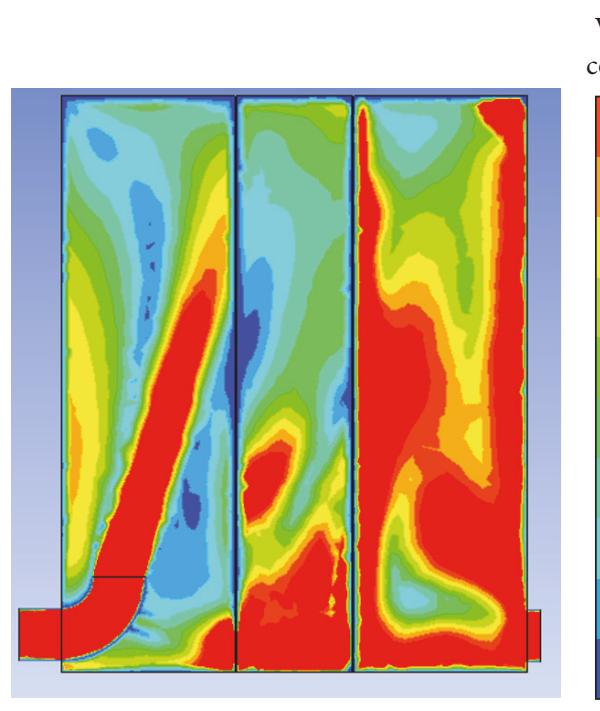

Velocity

contour 1

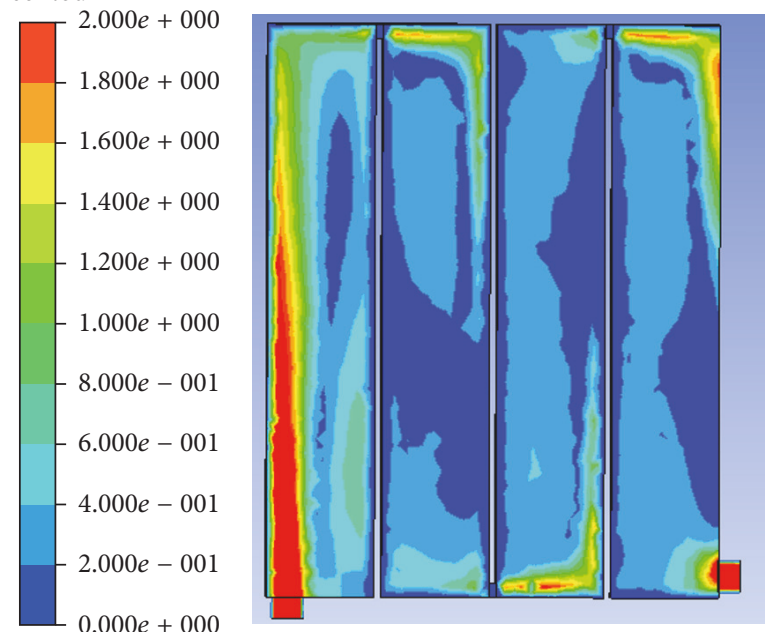

$\left(\mathrm{m} \mathrm{s}^{-1}\right)$

Velocity

contour 1
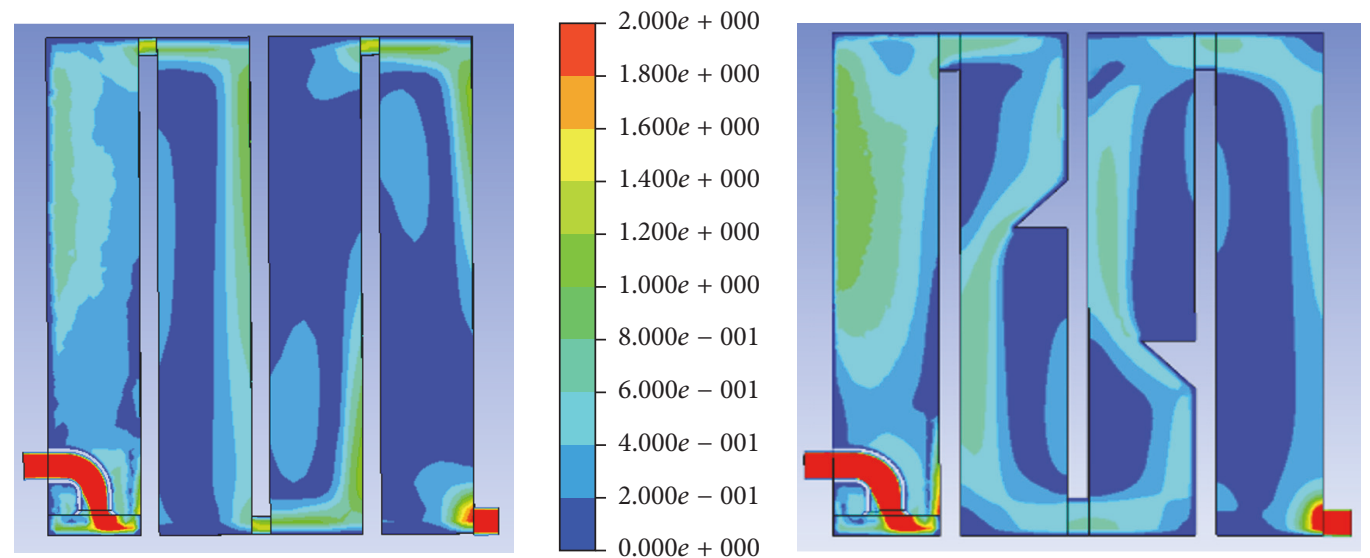

$\left(\mathrm{m} \mathrm{s}^{-1}\right)$

Figure 9: Velocity profiles of first, second, third, and final decay tank models.

TABLE 2: Decay tank models and CFD results.

\begin{tabular}{lcccccc}
\hline Models & Width $(\mathrm{m})$ & Length $(\mathrm{m})$ & Height $(\mathrm{m})$ & Section numbers & Mass flow rate $(\mathrm{kg} / \mathrm{s})$ & Flow residence time $(\mathrm{s})$ \\
\hline 1 & 1.5 & 2 & 5 & 3 & 700 & 14 \\
2 & 1.5 & 2 & 8 & 4 & 600 & 43 \\
3 & 1.5 & 2 & 8 & 4 & 600 & 54.7 \\
4 & 1.5 & 2 & 8 & 4 & 600 & 67 \\
\hline
\end{tabular}

passes though the connection region. To solve this problem, a triangular structure is incorporated as shown in Figure 6 in order to use both sides of the walls of the decay tank section and extend the flow distance.

Figure 9 shows the velocity profiles of the first, second, third, and final decay tank models with $2 \mathrm{~m} / \mathrm{s}$ legend. The red section of the first model indicates a velocity greater than $2 \mathrm{~m} / \mathrm{s}$ and, in some regions, a velocity greater than $5 \mathrm{~m} / \mathrm{s}$. In the second model, a velocity of $2 \mathrm{~m} / \mathrm{s}$ or more is not observed except for at the entrance portion and the connection region.
The velocity is still approximately $1.4-1.6 \mathrm{~m} / \mathrm{s}$. In the third model, the water is sprayed downward, and the velocity is lowered to less than $0.8 \mathrm{~m} / \mathrm{s}$. The flow fields of each section are developed along one side. In addition, the area of the connection region between the tanks has been increased, which causes the flow rate to decrease. In the second model, the velocity was approximately $1.4 \mathrm{~m} / \mathrm{s}$, but, after increasing the size of the connection, it was $0.8 \mathrm{~m} / \mathrm{s}$, which shows that the area increase in the connection part is advantageous. In the final model, the connecting part is further extended so 


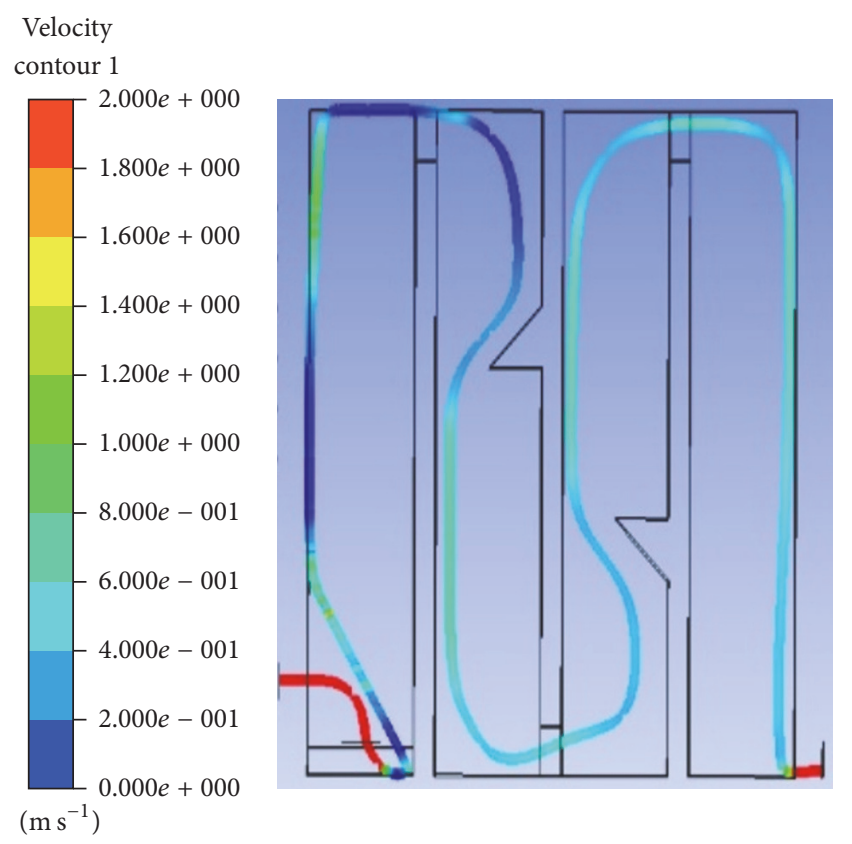

FIGURE 10: Streamline of fastest particles for final decay tank model.

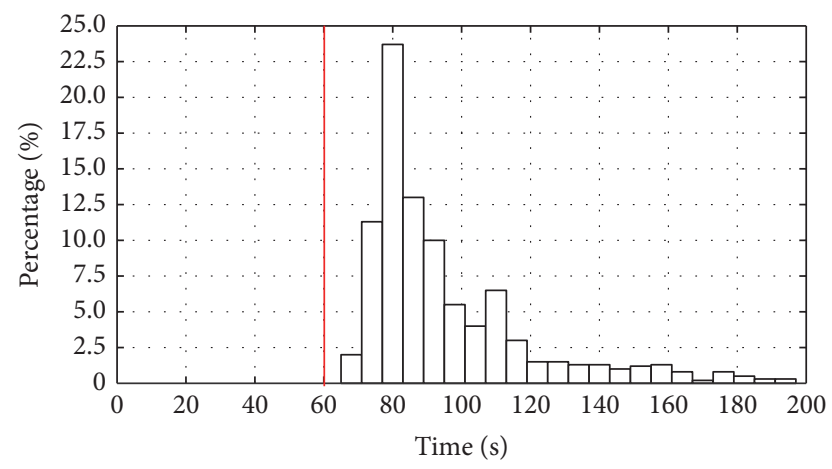

FIgURe 11: Particle distribution for final decay tank model.

that the velocity does not exceed $1 \mathrm{~m} / \mathrm{s}$ in any section other than the pipe. In addition, by installing a triangular barrier between the second and third sections, the flow residence time became longer than $60 \mathrm{~s}$ for the conservative design.

Figure 10 shows the streamline of the fastest particles for the final decay tank model. The particle distribution for the final decay tank model is shown in Figure 11. This model has been conservatively designed, and it has been confirmed that the residence time of all particles exceeds $60 \mathrm{~s}$, and the residence time of $70 \%$ of the particles stays within 60 to $100 \mathrm{~s}$.

4.2. Analysis Results of Siphon Breaker. If the siphon phenomenon occurs, the water may fall down to expose the reactor core to the air as shown in Figure 12, which can cause severe accidents. Here, the water illustrated as white color has the density of $998.2 \mathrm{~kg} / \mathrm{m}^{3}$, and the air as black color has the density of $1.22 \mathrm{~kg} / \mathrm{m}^{3}$. To prevent this, a decay tank can be used to create a more efficient device by designing a siphon breaker as shown in Figure 13.
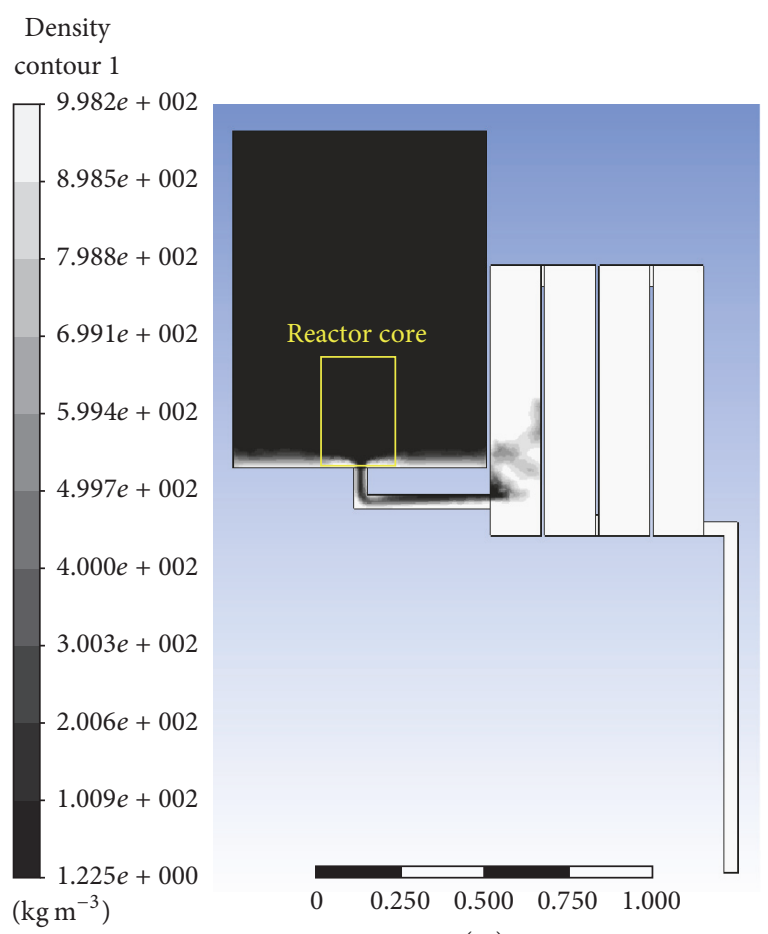

$(\mathrm{m})$

FIGURE 12: Simulation result of siphon phenomenon.

From the simulation results as shown in Figure 12, the outlet flow rate at the pipe rupture position is $1370 \mathrm{~kg} / \mathrm{s}$ and it is greater than $600 \mathrm{~kg} / \mathrm{s}$, which is the designed flow rate. This means that the gravity condition works reasonably well. In addition, if the reactor pool volume is $300 \mathrm{~m}^{3}$ and the outlet flow rate is $1370 \mathrm{~kg} / \mathrm{s}$, it will take approximately $220 \mathrm{~s}$ for the water in the reactor pool to be completely exhausted.

The siphon breaking phenomenon is simulated with an 18-inch siphon breaking valve as shown in Figure 13. The decay tank is disconnected between the third and fourth sections because of the siphon breaking. Therefore, the reactor pool is filled with the water after the siphon phenomenon is stopped. The siphon phenomenon is broken in approximately $5 \mathrm{~s}$ as per this calculation. In this research, the siphon breaking phenomenon has been successfully simulated with the integrated decay tank model.

\section{Conclusions}

In this study, the effectivity of an innovative integrated passive safety system for a research reactor is verified using CFD, and its design is then optimized based on the simulation results. The decay tank was conservatively designed with the minimum residence time of $60 \mathrm{~s}$. Using the DPM function, it was found that the flow residence time is at least $67 \mathrm{~s}$ and more than $70 \%$ of the particles, specially $\mathrm{N}-16$, have a residence time between 60 and $100 \mathrm{~s}$. With the help of a simulation, it is verified that the siphon phenomenon can be stopped by installing a siphon breaker in the third section of the decay tank. 


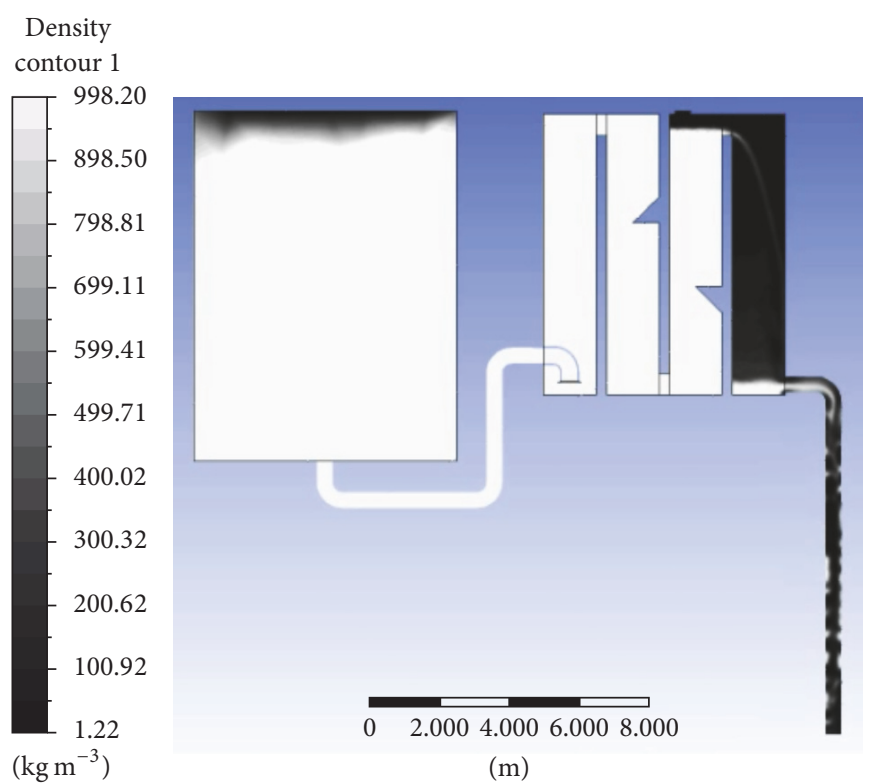

FIGURE 13: Simulation result of siphon breaking phenomenon.

Existing papers have been referred to understand the performance of decay tanks using perforated plates and a siphon breaker with a complex two-phase flow regime. This new integrated safety system provides the three functions of a decay tank, siphon breaker, and long-term cooling tank, respectively. Therefore, the available space can be efficiently used with a single structure. However, more detail design will be required to apply this integrated passive safety system to the fluid system of a new research reactor.

\section{Conflicts of Interest}

The authors declare that they have no conflicts of interest.

\section{Acknowledgments}

This work was supported by the National Research Foundation of Korea (NRF) grant funded by the Korean Government (Ministry of Science, ICT and Future Planning (MSIP)) (no. NRF-2016M2B2A9911771). Also, this paper was partially supported by the Education and Research Promotion Program of KOREATECH in 2017.

\section{References}

[1] N. Jeong, K. Seo, D.-Y. Chi, and J. Yoon, "Estimation of flow residence time in a decay tank for a pool type research reactor using CFD," Nuclear Engineering and Design, vol. 255, pp. 162168, 2013.

[2] N. Jeong, G. Roh, S. Kim, and J. Yoon, "Design evaluation of decay tank for a pool-type research reactor from the required minimum flow residence time point of view," Journal of Nuclear Science and Technology, vol. 51, no. 9, pp. 1064-1072, 2014.

[3] ANSYS, ANSYS FluenT Theory Guide, ANSYS Inc., Canonsburg, Pa, USA, 2009.
[4] J. McDonald and W. Marten, "A siphon break as a blocking valve," Standard Distribution Lists for Unclassified Scientific and Technical Reports NAA-SR-4050, 1959.

[5] D. T. Neill and A. G. Stephens, "Siphon breaker design requirements - final report," Idaho State University DOE/ER/12820-T1, Pocatello, Idaho, USA, 1993.

[6] F. Sakurai, "Study for improvements of performance of the test and research reactors," JAERI 99-016, 1999.

[7] S. H. Kang, Siphon Breaker Design on Research Reactor with Real-Scale Experiment, Pohang University of Science and Technology, 2015.

[8] K. Seo, S. H. Kang, J. M. Kim et al., "Experimental and numerical study for a siphon breaker design of a research reactor," Annals of Nuclear Energy, vol. 50, pp. 94-102, 2012.

[9] K.-Y. Lee and W.-S. Kim, "Theoretical study on loss of coolant accident of a research reactor," Nuclear Engineering and Design, vol. 309, pp. 151-160, 2016.

[10] K. Lee and W. Kim, "Development of siphon breaker simulation program for investing loss of coolant accident of a research reactor," Annals of Nuclear Energy, vol. 101, pp. 49-57, 2017.

[11] K. Y. Lee, S. H. Kim, and I. C. Lim, "A long-term cooling method for a research reactor," in Proceedings of the International Group on Research Reactor, IGORR, Daejron, South Korea, October 2013.

[12] K. W. Seo, Y. C. Park, J. K. Seo, D. Y. Chi, and J. H. Yoon, “Decay tank," Korea Patent 10-1166136, 2012. 


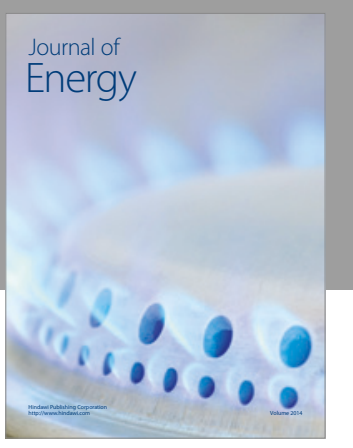

Journal of

Industrial Engineering
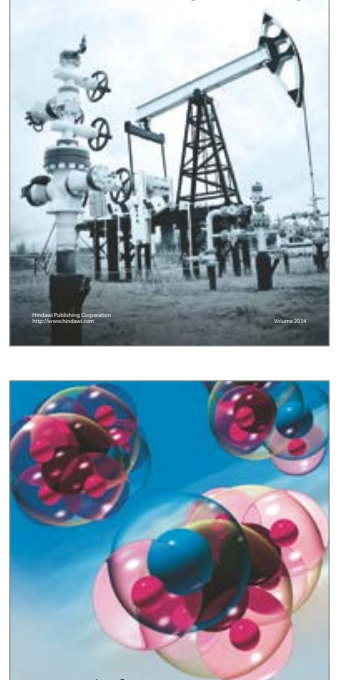

Fuels
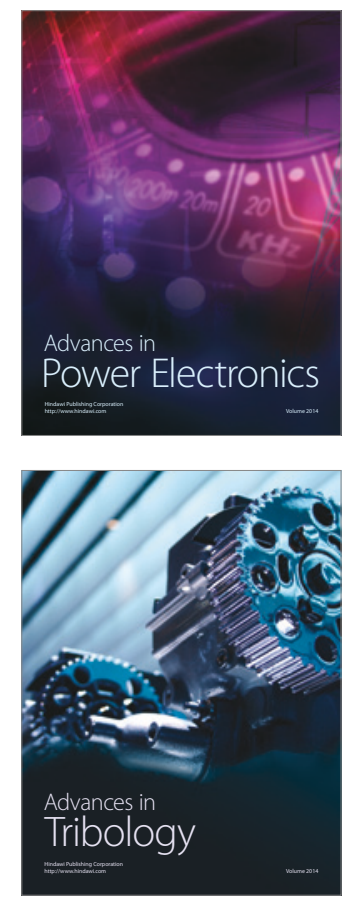
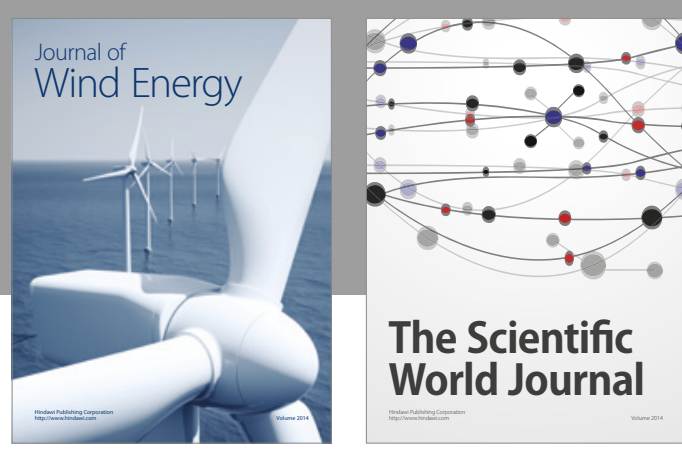

The Scientific World Journal
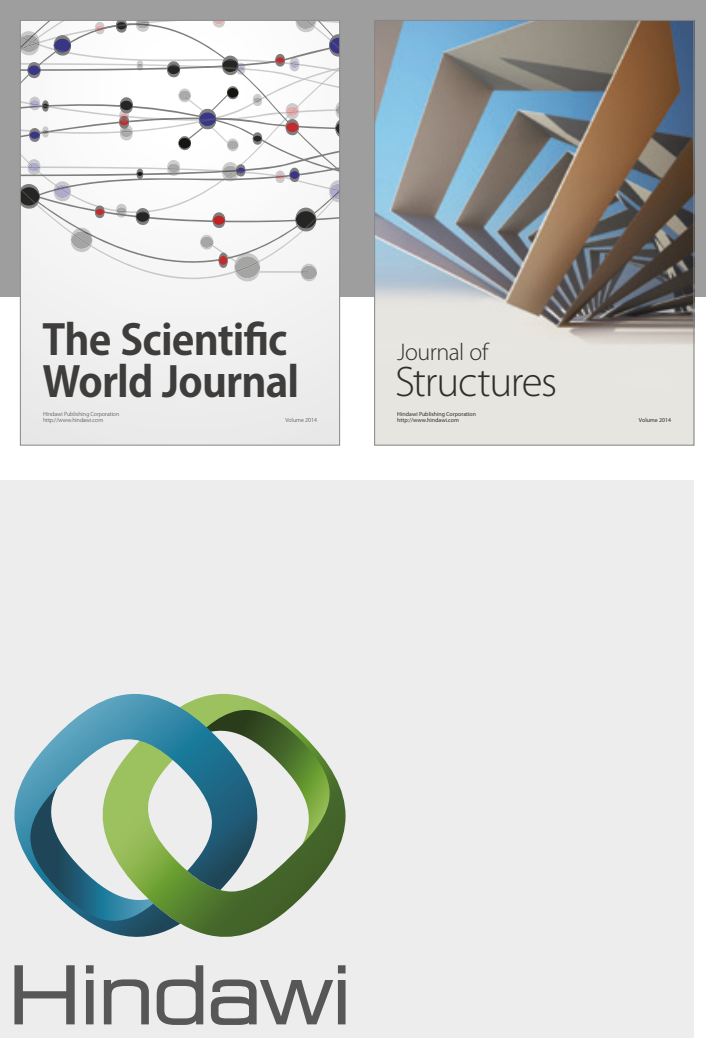

Submit your manuscripts at

https://www.hindawi.com
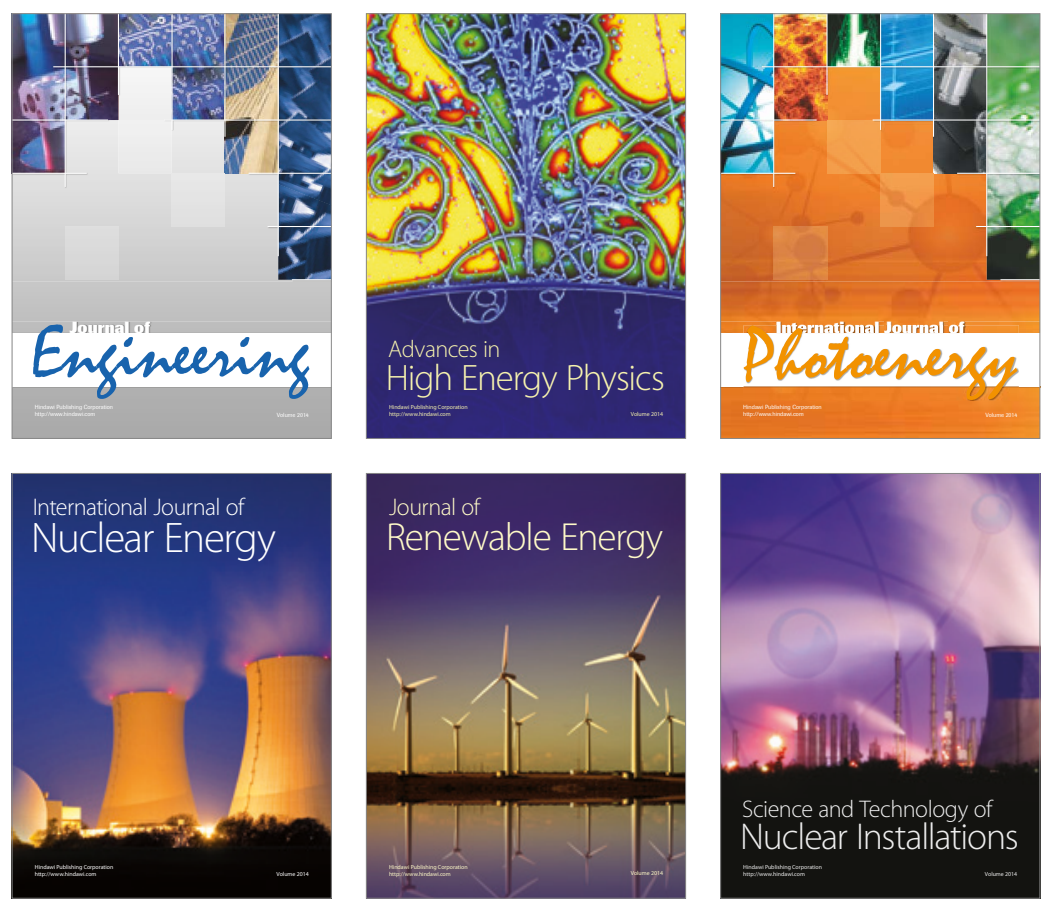

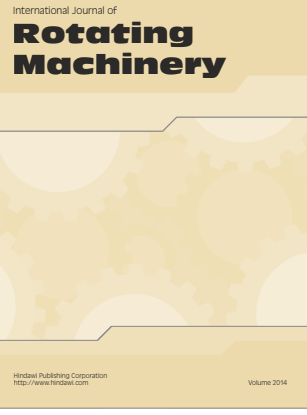

Journal of

Petroleum Engineering

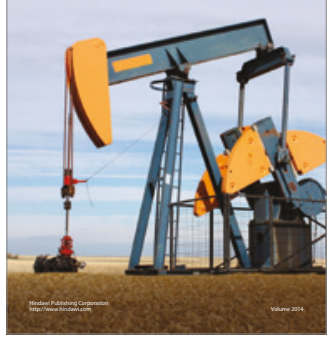

Journal of
Solar Energy
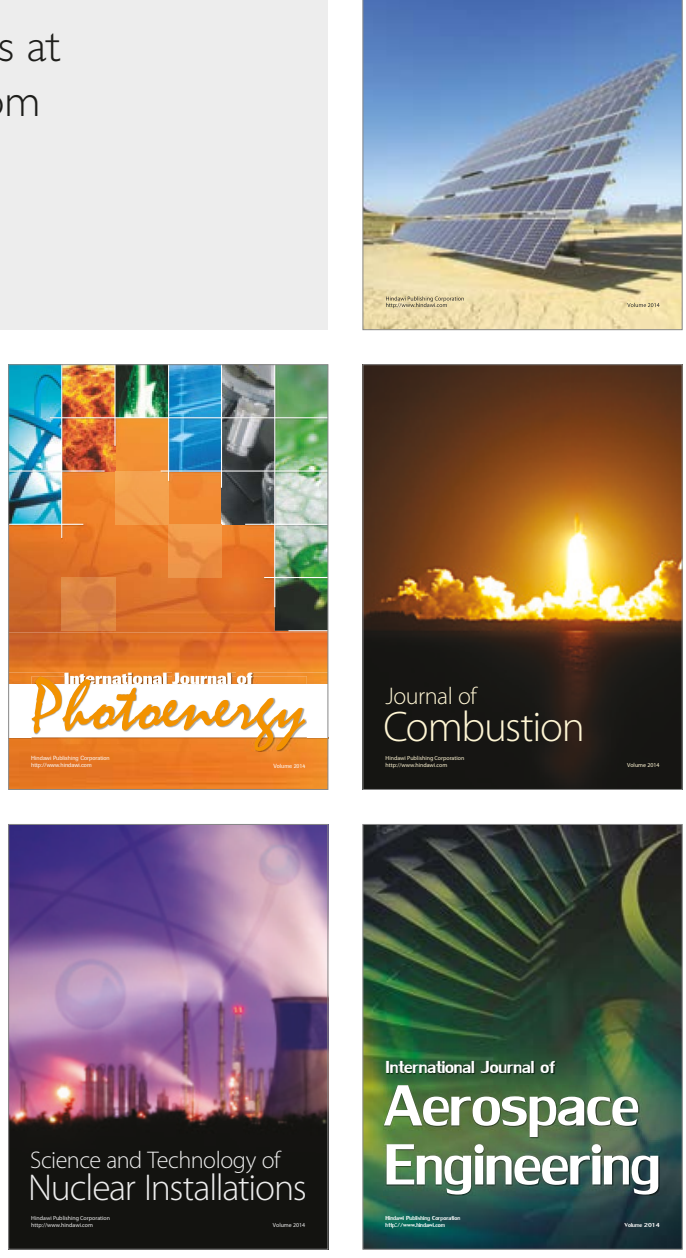